\title{
Pseudolaric acid B exerts antitumor activity via suppression of the Akt signaling pathway in HeLa cervical cancer cells
}

\author{
MINGQUN LI and LI HONG \\ Department of Gynecology, Renmin Hospital of Wuhan University, Wuhan, Hubei 430060, P.R. China
}

Received July 5, 2014; Accepted March 18, 2015

DOI: $10.3892 / \mathrm{mmr} .2015 .3615$

\begin{abstract}
Pseudolaric acid B (PAB) is a diterpene acid isolated from the bark of the root and trunk of Pseudolarix kaempferi Gordon (Pinaceae), which has demonstrated cytotoxic effects against various types of cancer. However, the mechanisms underlying the anticancer effects of PAB have remained to be elucidated. In the present study, the effects of PAB on the viability and apoptosis of HeLa cells were investigated by MTT assay, flow cytometric analysis of Annexin V-fluorescein isothiocyanate/propidium iodide staining, Rhodamine 123 staining and western blot analysis. The results demonstrated that PAB had antiproliferative and apoptosis-inducing effects on HeLa cells. PAB markedly inhibited HeLa cell viability in a time- and concentration-dependent manner. Flow cytometric analysis indicated that PAB induced apoptosis in HeLa cells in a dose-dependent manner. Treatment with PAB suppressed the expression of anti-apoptotic factor B cell lymphoma-2, and promoted the expression of pro-apoptotic factor Bcl-2-associated X protein. In addition, PAB induced an increase in Caspase-3 activity and loss of mitochondrial membrane potential, suggesting that this apoptosis may be mediated by mitochondrial pathways. Furthermore, the results of western blot analysis indicated that PAB was able to reduce Akt phosphorylation, thereby inhibiting the Akt pathway. These results suggested that PAB inhibited cell proliferation and induced apoptosis in HeLa cells, and that the anti-tumor effects of PAB were associated with inhibition of the Akt pathway. In conclusion, the results of the present study suggested that PAB may represent a novel therapeutic strategy for the treatment of human cervical cancer. However, additional studies are required to investigate the underlying apoptotic mechanisms.
\end{abstract}

Correspondence to: Professor Li Hong, Department of Gynecology, Renmin Hospital of Wuhan University, 238 Jiefang Road, Wuhan, Hubei 430060, P.R. China

E-mail: honglifk@163.com

Key words: pseudolaric acid B, HeLa cells, apoptosis, Akt pathway

\section{Introduction}

Cervical cancer is one of the most commonly diagnosed types of cancer, and the rates of mortality associated with this disease are ranked fourth highest of all malignant neoplasms amongst women worldwide (1). It has been estimated that there are $~ 500,000$ novel cases of cervical cancer diagnosed annually. Of those diagnosed in the USA, approximately one-third will succumb to the disease, and this number is significantly higher amongst women in developing countries, where $70 \%$ of cases are diagnosed at an advanced stage (2). Current treatment strategies include surgery, radiotherapy and chemotherapy. However, the majority of patients exhibit metastatic disease at the time of diagnosis or tumor recurrence following treatment. The survival of women with locally-advanced or metastatic disease has remained poor throughout the last two decades, and the long-term outlook has not significantly improved. Therefore, the identification and development of novel agents with high efficacy and low toxicity, that are able to overcome drug resistance and radioresistance, and have improved pharmacologic profiles is of significance worldwide.

Bioactive natural or synthetic chemical agents are frequently utilized in cancer therapeutics to reverse, suppress or prevent cancer progression. It has previously been reported that pseudolaric acid B (PAB) (3), a diterpene acid isolated from the bark of the root and trunk of Pseudolarix kaempferi Gordon (Pinaceae), possesses multiple biological activities, including anti-fungal (4), anti-fertility, cytotoxic, antimicrobial (5), anti-tubulin (6), anti-tumor (7) and anti-angiogenic activities (8). Previous studies have also revealed that PAB is able to induce growth inhibition, cell cycle arrest and apoptosis in various types of cancer, including ovarian cancer, lung cancer, prostate cancer and leukemia (9-11). However, to date, the mechanisms underlying the anticancer effects of PAB have remained to be elucidated.

The Akt signaling pathway has a critical role in the regulation of cell metabolism, growth, apoptosis, survival and tumorigenesis $(12,13)$, and activation of the Akt signaling pathway enhances the resistance of cancer cells to apoptosis and cell cycle progression, thus contributing to the survival and proliferation of cancer cells.

In the present study, the effects of $\mathrm{PAB}$ on cell viability, cell apoptosis and the Akt signaling pathway were examined in HeLa cervical cancer cells, and the antitumor mechanisms of PAB were analyzed. 


\section{Materials and methods}

Materials. Cervical cancer cells (HeLa) were obtained from the Cell Bank of the Shanghai Institute of Biochemistry and Cell Biology, Chinese Academy of Sciences (Shanghai, China). PAB was purchased from the China Institute of Biological Products (purity $>99.0 \%$; Beijing, China). RPMI-1640 medium, fetal bovine serum (FBS), penicillin-streptomycin, pancreatin, glutamine and the bicinchoninic acid (BCA) protein assay kit were purchased from Beyotime Institute of Biotechnology (Suzhou, China). An Annexin V-fluorescein isothiocyanate (FITC)/propidium iodide (PI) Apoptosis kit was purchased from Roche Diagnostics (Shanghai, China). MTT and Rhodamine 123 were purchased from Sigma-Aldrich (St. Louis, MO, USA). A Caspase-3 Colorimetric Assay kit was obtained from Nanjing Keygen Biotech Co. Ltd (Nanjing, China). The membranes were incubated overnight at $4^{\circ} \mathrm{C}$ with the following primary antibodies from Cell Signaling Technology, Inc. (Danvers, MA, USA): Rabbit polyclonal human Akt (\#9272S; 1:1,000), rabbit monoclonal phosphorylated-Akt (Ser473; p-Akt; \#4060S; 1:2,000), rabbit monoclonal p-glycogen synthase kinase (GSK)-3 $\beta$ (Ser9; \#5558S; 1:1,000), rabbit polyclonal B cell lymphoma-2 (Bcl-2; \#2876S; 1:1,000), rabbit polyclonal Bcl-2-associated X protein (Bax; \#2772S; 1:1,000) and rabbit polyclonal $\beta$-actin (\#4967S; 1:1,000). The anti-rabbit horseradish peroxidase-conjugated secondary antibodies $(1: 1,000)$ were purchased from Wuhan Boster Biotechnology Co., Ltd. (Wuhan, China). All other chemicals were of reagent grade and obtained from commercial sources.

Cell culture. HeLa cells were cultured in RPMI-1640 medium supplemented with heat-inactivated $10 \%$ FBS and $1 \%$ antibiotics (100 IU penicillin and $100 \mu \mathrm{g} / \mathrm{ml}$ streptomycin) in a humidified incubator at $37^{\circ} \mathrm{C}$ and $5 \% \mathrm{CO}_{2}$. Logarithmically growing cells were used in all the subsequent experiments.

Cell viability. An MTT assay was used to analyze the viability of HeLa cells following PAB treatment. Briefly, HeLa cells were seeded into 96 -well plates $\left(6.0 \times 10^{3}\right.$ cells/well). Following cellular adhesion, the medium was replaced with fresh medium supplemented with various concentrations of PAB $(0$, $2,4,8$ and $16 \mu \mathrm{mol} / \mathrm{l})$ and further cultured for the indicated time-periods (24, 48 and $72 \mathrm{~h})$. The control culture received only the culture medium. Following incubation with PAB or culture medium, MTT was added at a concentration of $5 \mathrm{mg} / \mathrm{ml}$, and the cells were incubated for $4 \mathrm{~h}$ at $37^{\circ} \mathrm{C}$. The medium was subsequently discarded and dimethyl sulfoxide (Sigma-Aldrich) was added to dissolve the MTT formazan crystals. The absorbance of each well was determined using a microplate reader (Bio-Rad 680; Bio-Rad Laboratories, Inc., Hercules, CA, USA) at a wavelength of $570 \mathrm{~nm}$. The wells without PAB and the free cells (culture medium alone) were used as background. The cell growth inhibition rate was defined as the relative absorbance of treated versus untreated cells.

Cell apoptosis assay. In order to quantify apoptosis, cells were stained with Annexin V and PI using an Annexin V-FITC/PI Apoptosis kit according to the manufacturer's instructions.
Briefly, HeLa cells were cultured in six-well plates $\left(2 \times 10^{5}\right.$ cells/well) and allowed to adhere overnight. Following cellular adhesion, the cells were treated for a further $48 \mathrm{~h}$ with $\operatorname{PAB}(0,2,4$ and $8 \mu \mathrm{mol} / 1)$. Subsequently, the cells were washed twice with cold phosphate-buffered saline (PBS; Wuhan Boster Biotechnology Co., Ltd.) and resuspended in Annexin V-FITC binding buffer. Annexin V-FITC was then added and mixed gently, prior to incubation of the cells for $15 \mathrm{~min}$ at room temperature in the dark. The mixture was then centrifuged at $1,000 \mathrm{x}$ g for $5 \mathrm{~min}$ at room temperature and resuspended in Annexin V-FITC binding buffer. PI staining solution was then added and combined. The cells were kept on ice in the dark and immediately analyzed by flow cytometry (FACScan; BD Biosciences, San Diego, CA, USA).

Caspase-3 activity determination. A Caspase-3 colorimetric assay kit was used to evaluate Caspase-3 activity. The assay is based on the cleavage of DEVD-pNA, the chromogenic substrate, by Caspase-3. HeLa cells were seeded into 96-well white opaque plates $\left(6 \times 10^{3}\right.$ cells/well) and a corresponding optically transparent 96-well plate, and allowed to adhere overnight, according to the manufacturer's instructions. Following cellular adhesion, cells were treated with $\operatorname{PAB}(0,2$, 4 and $8 \mu \mathrm{mol} / \mathrm{l}$ ) for $48 \mathrm{~h}$. At the end of the incubation period, cells were harvested, lysed in chilled lysis buffer (Beyotime Institute of Biotechnology, Suzhou, China) on ice for $10 \mathrm{~min}$ and centrifuged for $5 \mathrm{~min}$ at 1,500 x g. Subsequently, Caspase substrate solution, containing the specific peptide substrate, was added to the supernatant and incubated for $2 \mathrm{~h}$ at $37^{\circ} \mathrm{C}$. Finally, Caspase- 3 activity was spectrophotometrically quantified at a wavelength of $405 \mathrm{~nm}$ using the UV-2250 Spectrophotometer (Shimadzu Corporation, Kyoto, Japan).

Measurement of mitochondrial membrane potential. Rhodamine 123 staining was used to measure the mitochondrial membrane potential. HeLa cells were cultured in six-well plates $\left(2 \times 10^{5}\right.$ cells/well $)$ and allowed to attach overnight. The cells were then treated for a further $48 \mathrm{~h}$ with PAB $(0,2,4$ and $8 \mu \mathrm{mol} / \mathrm{l})$ as mentioned above. Cells were harvested, washed twice with PBS, incubated with $1 \mathrm{ml}$ Rhodamine 123 staining solution $(1 \mu \mathrm{g} / \mathrm{ml})$ at $37^{\circ} \mathrm{C}$ in the dark for $30 \mathrm{~min}$, washed twice with PBS and centrifuged at $500 \mathrm{xg}$ for $10 \mathrm{~min}$. Finally, absorbance was determined using a spectrofluorometer (F-2500; Hitachi, Ltd., Tokyo, Japan), at an excitation wavelength of $505 \mathrm{~nm}$ and an emission wavelength of $534 \mathrm{~nm}$.

Western blot assay. Protein expression levels were analyzed by western blotting. Briefly, HeLa cells were seeded in six-well plates at a density of $2.5 \times 10^{5}$ cells/well and were incubated overnight at $37^{\circ} \mathrm{C}$ prior to treatment. Following treatment of the cells with PAB $(0,2,4$ and $8 \mu \mathrm{mol} / 1$, respectively) for $48 \mathrm{~h}$, the cells were washed with PBS, lysed with lysis buffer and incubated at $4^{\circ} \mathrm{C}$ for $1 \mathrm{~h}$. The extracts were cleared by centrifugation at $1,900 \mathrm{xg}$ for $20 \mathrm{~min}$ at $4^{\circ} \mathrm{C}$. The protein concentration was determined using a $\mathrm{BCA}$ protein assay kit according to the manufacturer's instructions. Protein samples were loaded at a concentration of $40 \mu \mathrm{g} / \mathrm{lane}$, separated by $12.5 \%$ SDS-PAGE and transferred onto a nitrocellulose membrane (EMD Millipore, Bedford, MA, USA) using a wet transfer system. The membrane was blocked with $10 \%$ non-fat dried milk in 


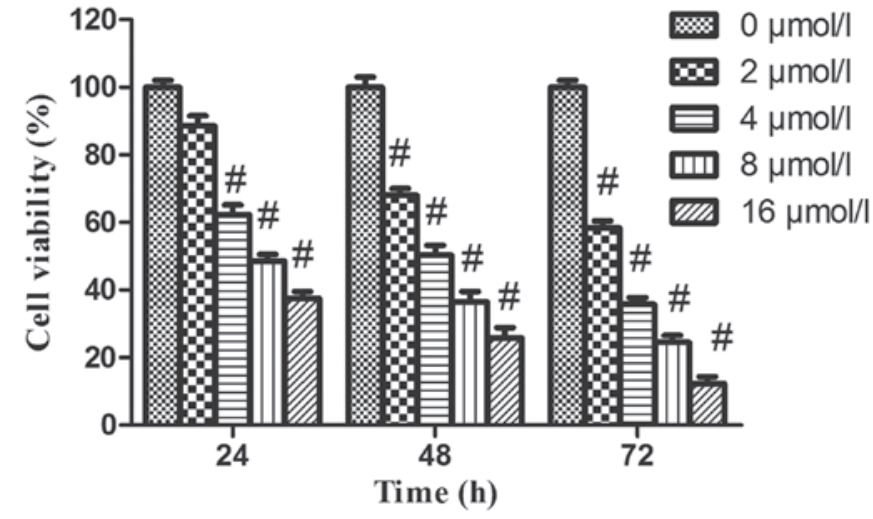

Figure 1. PAB inhibits the viability of HeLa cells in vitro. HeLa cells were treated with increasing concentrations of PAB $(0,2,4,8$ and $16 \mu \mathrm{mol} / \mathrm{l})$ for $0,24,48$ and $72 \mathrm{~h}$ and an MTT assay was subsequently used to assess the cell viability. The number of viable cells was proportional to the absorbance at $570 \mathrm{~nm}$. Treatment with PAB induced a dose- and time-dependent inhibition of cell viability. ${ }^{\#} \mathrm{P}<0.05$ vs. $0 \mu \mathrm{mol} / 1 \mathrm{PAB}$. PAB, pseudolaric acid B.

Tris-buffered saline with $0.1 \%$ Tween-20 (pH 8.0; Beyotime Institute of Biotechnology, Shanghai, China) and then incubated with primary antibodies against Akt, p-Akt, p-GSK-3 $\beta$, $\mathrm{Bax}, \mathrm{Bcl}-2$ and actin overnight at $4^{\circ} \mathrm{C}$. The membrane was subsequently incubated with the appropriate horseradish peroxidase-conjugated secondary antibodies at a dilution of 1:3,000. The results were detected with an enhanced chemiluminescence system (EMD Millipore) and Hyperfilm X-ray film (Kodak, Rochester, NY, USA).

Statistical analysis. SPSS software, version 13.0 (SPSS, Inc., Chicago, IL, USA) was used for the statistical analysis. All continuous values are expressed as the mean \pm standard deviation. Student's t-test was used to compare the differences between two groups. $\mathrm{P}<0.05$ was considered to indicate a statistically significant difference.

\section{Results}

$P A B$ decreases the viability of HeLa cells. In order to evaluate the effects of PAB on cell growth, HeLa cells were treated with increasing concentrations of PAB for various time-periods, and the viability of the cells was assessed by MTT assay. As revealed in Fig. 1, following PAB treatment, the viability of HeLa cells was significantly decreased in a dose- and time-dependent manner.

PAB induces apoptosis in HeLa cells. To determine whether the growth-inhibitory effect of PAB was associated with the induction of apoptosis, HeLa cells treated with PAB for $48 \mathrm{~h}$ were analyzed using flow cytometry. As indicated in Fig. 2, the proportion of apoptotic cells increased from 15.4 to $38.6 \%$ following PAB treatment, in a dose-dependent manner, indicating that PAB may inhibit the growth of HeLa cells via the induction of apoptosis.

PAB inhibits Akt kinase activation in HeLa cells. It has previously been reported that aberrant activation of the Akt signaling pathway occurs in a number of human malignancies (14). Therefore, the present study aimed to assess the effects of PAB
A

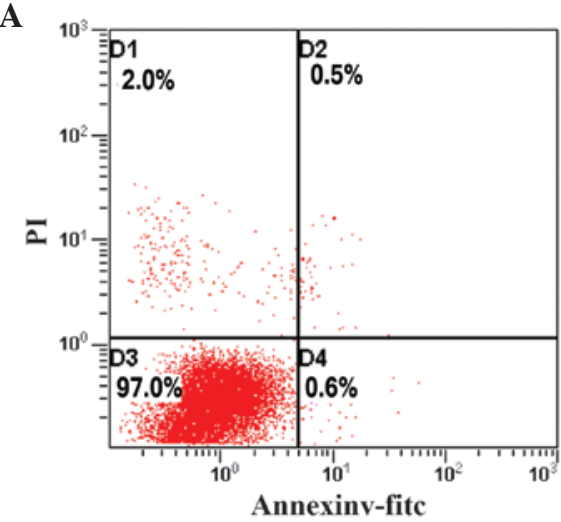

B

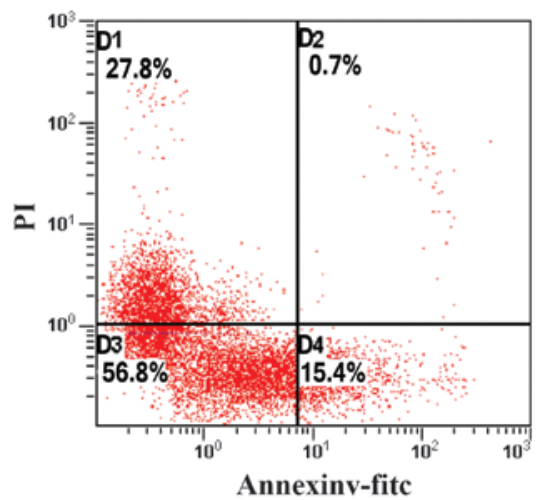

C
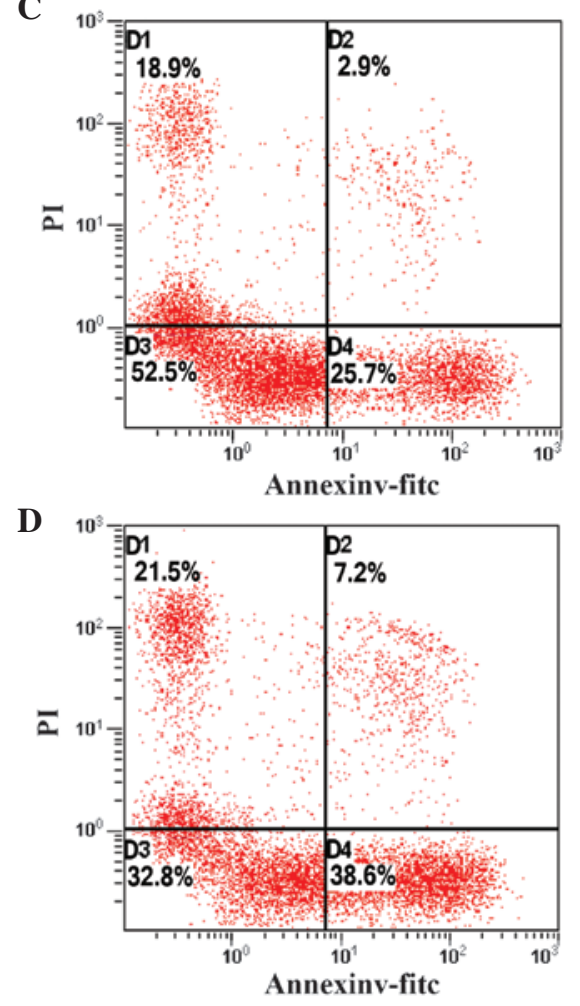

Figure 2. PAB induces apoptosis in HeLa cells. HeLa cells were treated with various concentrations of $\mathrm{PAB}$ for $48 \mathrm{~h}$, prior to the analysis of cell apoptosis by flow cytometry. (A) $0 \mu \mathrm{mol} / 1 \mathrm{PAB}$, (B) $2 \mu \mathrm{mol} / 1 \mathrm{PAB}$, (C) $4 \mu \mathrm{mol} / 1 \mathrm{PAB}$ and (D) $8 \mu \mathrm{mol} / 1$. PAB, pseudolaric acid B; PI, propidium iodide; fitc, fluorescein isothiocyanate.

on the Akt signaling pathway. HeLa cells were exposed to 0,2 , 4 and $8 \mu \mathrm{mol} / \mathrm{l} \mathrm{PAB}$ for $48 \mathrm{~h}$ and the expression of $\mathrm{p}-\mathrm{AKT}$ was assessed by western blot analysis. As demonstrated in Fig. 3, 


\section{$0 \mu \mathrm{mol} / \mathrm{l} \quad 2 \mu \mathrm{mol} / \mathrm{l} \quad 4 \mu \mathrm{mol} / \mathrm{l} \quad 8 \mu \mathrm{mol} / \mathrm{l}$}

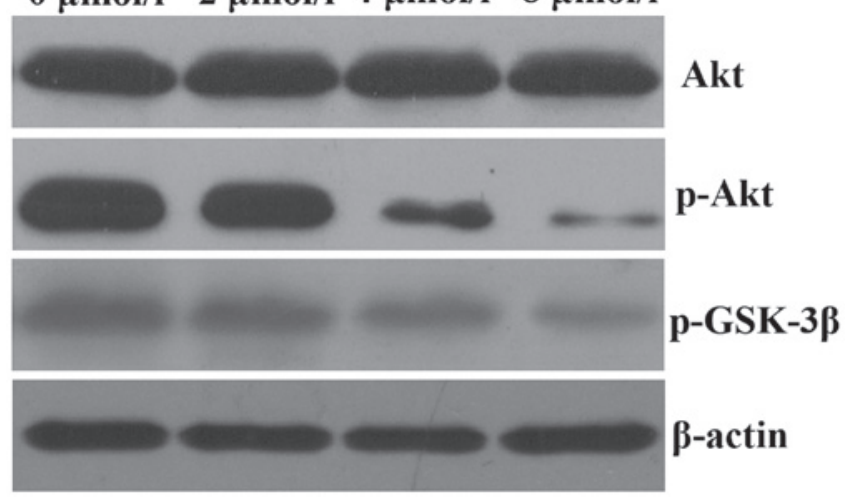

Figure 3. PAB inhibits Akt phosphorylation and the Akt pathway in HeLa cells. HeLa cells were treated with PAB $(0,2,4$ and $8 \mu \mathrm{mol} / 1)$ for $48 \mathrm{~h}$, and the protein expression levels of Akt, p-Akt and p-GSK-3 $\beta$ were measured by western blotting. PAB, pseudolaric acid B; p-, phosphorylated; GSK-3 $\beta$, glycogen synthase kinase-3 $\beta$.

\section{$0 \mu \mathrm{mol} / \mathrm{l} \quad 2 \mu \mathrm{mol} / \mathrm{l} \quad 4 \mu \mathrm{mol} / \mathrm{l} \quad 8 \mu \mathrm{mol} / \mathrm{l}$}

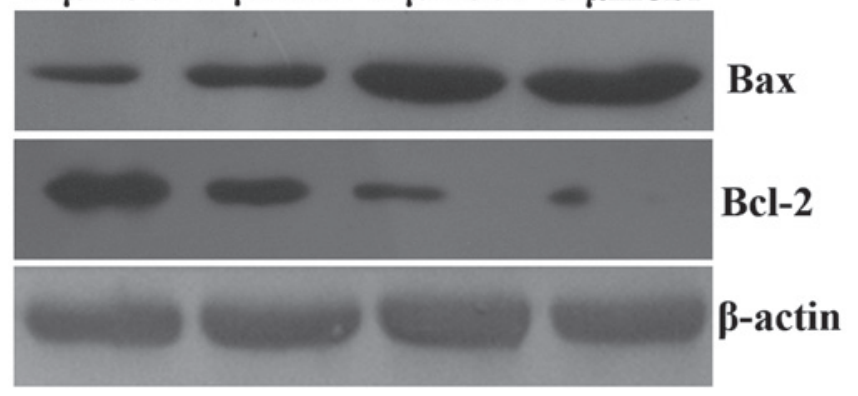

Figure 4. PAB promotes the expression of Bax and downregulates Bcl-2 expression in HeLa cells. HeLa cells were treated with PAB $(0,2,4$ and $8 \mu \mathrm{mol} / \mathrm{l}$ ) for $48 \mathrm{~h}$, and the protein levels of Bax and Bcl-2 were measured by western blotting. PAB, pseudolaric acid B; Bcl-2, B cell lyphoma-2; Bax, Bcl-2-associated X protein.

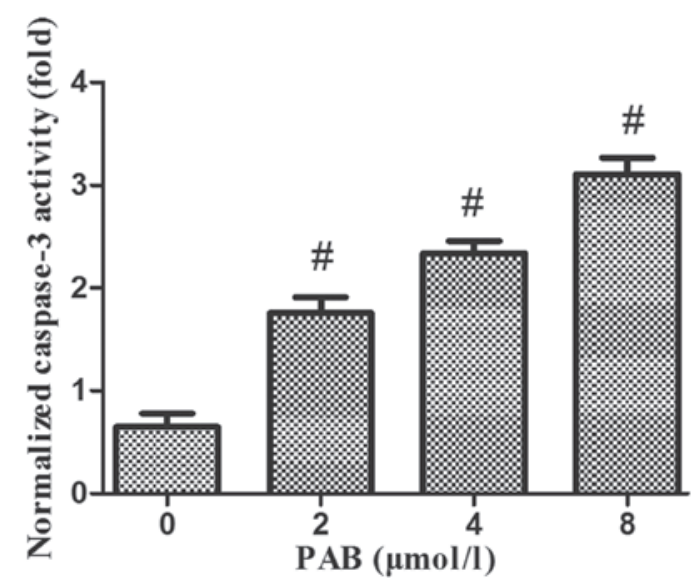

Figure 5. PAB increases the activity of Caspase-3 in HeLa cells. HeLa cells were treated with $0,2,4$ and $8 \mu \mathrm{mol} / 1 \mathrm{PAB}$ for $48 \mathrm{~h}$, and the relative Caspase- 3 activity was analyzed using a Caspase- 3 colorimetric assay kit. ${ }^{\#} \mathrm{P}<0.05$ vs. $0 \mu \mathrm{mol} / 1 \mathrm{PAB}$. PAB, pseudolaric acid B;

treatment of HeLa cells with PAB for $48 \mathrm{~h}$ decreased the expression of p-AKT in a dose-dependent manner; however, total Akt expression levels remained unchanged. The expres-

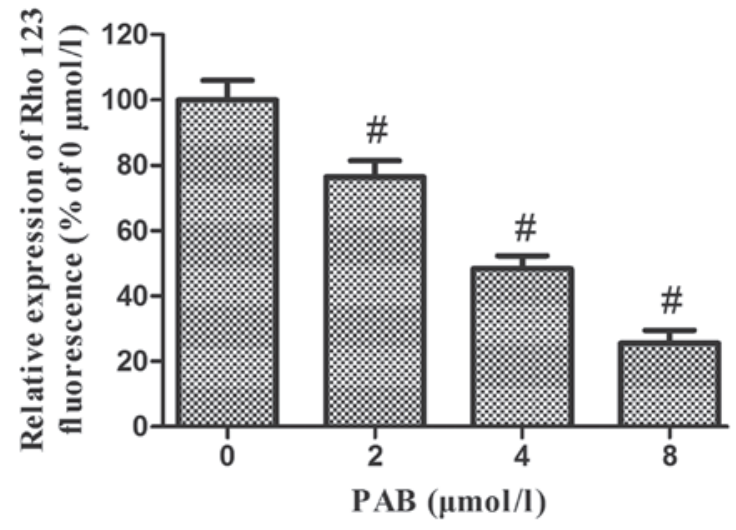

Figure 6. PAB decreases the mitochondrial membrane potential in HeLa cells. PAB significantly decreased Rhodamine 123 fluorescence intensity in HeLa cells treated with PAB for $48 \mathrm{~h}$, suggesting that PAB decreases the mitochondrial membrane potential and therefore $\mathrm{PAB}$ treatment may induce apoptosis via the mitochondrial apoptosis pathway. ${ }^{\#} \mathrm{P}<0.05 \mathrm{vs} .0 \mu \mathrm{mol} / 1$ PAB. PAB, pseudolaric acid B; Rho 123, Rhodamine 123.

sion of p-GSK-3 $\beta$, a downstream effector of Akt, was also decreased.

$P A B$ upregulates caspase-3 activity and alters the protein expression levels of Bax and Bcl-2 in HeLa cells. In order to elucidate the mechanisms underlying the induction of apoptosis by PAB in HeLa cells, mitochondrial features of the intrinsic apoptotic pathway were analyzed. Proapoptotic members of the Bcl-2 family, including Bax, are required for the induction of mitochondrial dysfunction during apoptosis. The protein expression levels of Bax and Bcl-2 were assessed by western blotting. The results indicated that treatment of HeLa cells with increasing doses of PAB for $48 \mathrm{~h}$ enhanced the expression of Bax and downregulated the expression of antiapoptotic Bcl-2 (Fig. 4). In addition, the activity of caspase-3 was upregulated (Fig. 5).

$P A B$ decreases the mitochondrial membrane potential in HeLa cells. A variety of studies have demonstrated that the disruption of mitochondrial integrity is a critical stage, which occurs in cells undergoing apoptosis, and a decrease in mitochondrial membrane potential is associated with such mitochondrial dysfunction (15-17). A loss of mitochondrial membrane potential therefore has a significant role in facilitating mitochondrial-mediated apoptosis. As shown in Fig. 6, Rhodamine 123 fluorescence intensity was significantly decreased following treatment of HeLa cells with increasing concentrations of PAB for $48 \mathrm{~h}$, suggesting that PAB treatment of HeLa cells may induce apoptosis via the mitochondrial apoptosis pathway.

\section{Discussion}

Cervical cancer, a common gynecological malignancy, is one of the leading causes of cancer-associated mortality amongst females worldwide (18). There are $>500,000$ novel cases of cervical cancer diagnosed annually, as well as $>270,000$ mortalities, worldwide. Greater than $85 \%$ of these cases and mortalities occur in developing countries (1). The treatment strategy for cervical cancer depends on the disease status at 
the time of diagnosis. For patients with earlier-stage disease, standard treatments focus on radical surgery, whereas the treatment for patients with bulky, locally-advanced or metastatic stage disease is more often focused on radical radiotherapy or primary concurrent chemoradiation $(19,20)$. Although there have been marked improvements in the treatment of various types of cancer over the past 30 years, the prognosis of patients with locally-advanced or metastatic cervical cancer has remained virtually unchanged. Therefore, the development of innovative treatment strategies is required, in order to improve the prognosis of the disease.

PAB has been reported to induce growth inhibition, cell cycle arrest and apoptosis in various types of cancer in vitro and in vivo (9-11). However, the underlying mechanisms of these effects have remained to be elucidated. In the present study, it was demonstrated that PAB effectively inhibited HeLa cell proliferation in a dose- and time-dependent manner. Whether the growth-inhibitory effect of PAB was associated with the induction of apoptosis was also examined, and the results of Annexin V/PI staining indicated that treatment of HeLa cells with PAB induced cell apoptosis in a concentration-dependent manner.

It has been universally acknowledged that alterations in the balance between cell proliferation and apoptosis represent a significant factor in the process of carcinogenesis, and that the induction of apoptosis is one of the most effective approaches for tumor therapies. Apoptosis is a highly regulated process, by which cells undergo inducible non-necrotic cellular suicide, and involves the coordination of anti- and pro-apoptotic proteins (21). Pro-apoptotic members of the Bcl-2 family, including Bax, are necessary for the induction of mitochondrial dysfunction during apoptosis. The results of western blot analysis indicated that the expression of pro-apoptotic factor Bax was markedly upregulated, whereas expression of the anti-apoptotic factor Bcl-2 was significantly reduced following treatment with PAB. Furthermore, caspase-3 activation was significantly enhanced. In addition, treatment of HeLa cells with PAB also induced a decrease in the mitochondrial membrane potential. These results suggested that Bcl-2 inhibited Bax activity, which reduced the mitochondrial membrane potential, resulting in caspase-3 upregulation and inducing cell apoptosis (22). Together, these results indicated that PAB was able to induce apoptosis in HeLa cells via activation of the mitochondrial apoptosis pathway. Additionally, the mechanisms underlying the decrease in cell proliferation and the enhancement of apoptosis in HeLa cells induced by PAB were investigated.

Akt (also known as protein kinase B), a subfamily of the serine/threonine kinase family, has a vital role in cell metabolism, growth, apoptosis and tumorigenesis $(12,13)$. Once activated, p-Akt, a significant regulatory factor involved in multiple apoptotic processes, resists apoptosis through antagonization and inactivation of various components of the apoptotic cascade, including pro-apoptotic factor Bax (23). It has also been reported that activated Akt may induce or suppress downstream target proteins, including Bcl-2-associated death promoter, caspase- 9 , nuclear factor- $\kappa \mathrm{B}, \mathrm{GSK}-3 \beta$ and forkhead transcription factor Foxo1, thereby regulating proliferation, differentiation, apoptosis and metastasis (24-26). It has been confirmed that Akt and p-Akt are overexpressed in a variety of human malignancies $(14,27)$, and aberrant activation of the
Akt pathway may also directly or indirectly interact with other pathways $(28,29)$. Therefore, inhibition of the Akt pathway may be an effective approach for the prevention and treatment of certain malignancies. In the present study, it was demonstrated that Akt phosphorylation was decreased following PAB treatment. Furthermore, the PAB-induced inhibition of Akt phosphorylation was coupled with the suppression of p-GSK-3 $\beta$. These results demonstrated that inhibition of Akt phosphorylation may be one of the underlying mechanisms of PAB-induced apoptosis.

In conclusion, the results of the present study demonstrated that PAB inhibited cell proliferation and induced apoptosis in HeLa cells, and that the anti-tumor effects of PAB were associated with the inhibition of Akt phosphorylation, thus suppressing the Akt signaling pathway. These results broaden the potential medicinal applications of PAB, and additional studies are required to further investigate the underlying apoptotic mechanisms. It was hypothesized that PAB may function as a novel therapeutic agent for the treatment of human cervical cancer, alone or in combination with conventional therapeutics.

\section{Acknowledgements}

The present study was supported by a grant from the Natural Science Foundation of Hubei Province (no. 2010CDB06903).

\section{References}

1. Jemal A, Bray F, Center MM, Ferlay J, Ward E and Forman D: Global cancer statistics. CA Cancer J Clin 61: 69-90, 2011.

2. Tewari KS, Sill MW, Long HJ III, et al: Improved survival with bevacizumab in advanced cervical cancer. N Engl J Med 370: 734-743, 2014.

3. Yan Z, Hua H, Xu Y and Samaranayake LP: Potent antifungal activity of pure compounds from Traditional Chinese Medicine extracts against six oral Candida species and the synergy with fluconazole against azole-resistant Candida albicans. Evid Based Complement Alternat Med 2012: 106583, 2012.

4. Zhang J, Yan LT, Yuan EL, et al: Antifungal activity of compounds extracted from cortex Pseudolaricis against Colletotrichum gloeosporioides. J Agric Food Chem 62: 4905-4910, 2014.

5. Chiu P, Leung LT and Ko BC: Pseudolaric acids: isolation, bioactivity and synthetic studies. Nat Prod Rep 27: 1066-1083, 2010.

6. Sarkar T, Nguyen TL, Su ZW, et al: Interaction of pseudolaric acid B with the colchicine site of tubulin. Biochem Pharmacol 84: 444-450, 2012.

7. Yu B, Yue DM, Shu LH, Li NJ and Wang JH: Pseudolaric acid B induces caspase-dependent cell death in human ovarian cancer cells. Oncol Rep 31: 849-857, 2014.

8. Miao ZH, Feng JM and Ding J: Newly discovered angiogenesis inhibitors and their mechanisms of action. Acta Pharmacol Sin 33: 1103-1111, 2012

9. Guan T and Yang Y: Role of pseudolaric acid B in A549 lung cancer cell proliferation and apoptosis. Mol Med Rep 9: 144-148, 2014.

10. Ma G, Chong L, Li XC, Khan IA, Walker LA and Khan SI: Selective inhibition of human leukemia cell growth and induction of cell cycle arrest and apoptosis by pseudolaric acid B. J Cancer Res Clin Oncol 136: 1333-1340, 2010.

11. Tong J, Yin S, Dong Y, Guo X, Fan L, Ye M and Hu H: Pseudolaric acid $\mathrm{B}$ induces caspase-dependent apoptosis and autophagic cell death in prostate cancer cells. Phytother Res 27: 885-891, 2013.

12. Brazil DP, Yang ZZ and Hemmings BA: Advances in protein kinase B signalling: AKTion on multiple fronts. Trends Biochem Sci 29: 233-242, 2004.

13. Manning BD and Cantley LC: AKT/PKB signaling: navigating downstream. Cell 129: 1261-1274, 2007.

14. Vivanco I and Sawyers CL: The phosphatidylinositol 3-kinase AKT pathway in human cancer. Nat Rev Cancer 2: 489-501, 2002. 
15. Huang B, Meng N, Zhao B, Zhao J, Zhang Y, Zhang S, and Miao J: Protective effects of a synthesized butyrolactone derivative against chloroquine-induced autophagic vesicle accumulation and the disturbance of mitochondrial membrane potential and $\mathrm{Na}+\mathrm{K}+$-ATPase activity in vascular endothelial cells. Chem Res Toxicol 22:471-475, 2009.

16. Galluzzi L, Vitale I, Abrams JM, et al: Molecular definitions of cell death subroutines: Recommendations of the Nomenclature Committee on Cell Death 2012. Cell Death Differ 19: 107-120,2012.

17. Vandenabeele P, Galluzzi L, Vanden Berghe T and Kroemer G: Molecular mechanisms of necroptosis: An ordered cellular explosion. Nat Rev Mol Cell Biol 11: 700-714, 2010.

18. Ferlay J, Shin HR, Bray F, Forman D, Mathers C and Parkin DM: Estimates of worldwide burden of cancer in 2008: GLOBOCAN 2008. Int J Cancer 127: 2893-2917, 2010.

19. Green JA, Kirwan JM, Tierney JF, Symonds P, Fresco L, Collingwood M and Williams CJ: Survival and recurrence after concomitant chemotherapy and radiotherapy for cancer of the uterine cervix: a systematic review and meta-analysis. Lancet 358: 781-786, 2001.

20. Rogers L, Siu SS, Luesley D, Bryant A and Dickinson HO Radiotherapy and chemoradiation after surgery for early cervical cancer. Cochrane Database Syst Rev 5: CD007583, 2012.

21. Tang D, Lotze MT, Kang R and Zeh HJ: Apoptosis promotes early tumorigenesis. Oncogene 30: 1851-1854, 2011.

22. Youle RJ and Strasser A: The BCL-2 protein family: opposing activities that mediate cell death. Nat Rev Mol Cell Biol 9: 47-59, 2008.
23. Coffer PJ, Jin J and Woodgett JR: Protein kinase B (c-Akt): a multifunctional mediator of phosphatidylinositol 3-kinase activation. Biochem J 335: 1-13, 1998.

24. Wang Z, Yang J, Fisher T, Xiao H, Jiang Y and Yang C: Akt activation is responsible for enhanced migratory and invasive behavior of arsenic-transformed human bronchial epithelial cells. Environ Health Perspect 120: 92-97, 2012.

25. Mosca E, Barcella M, Alfieri R, Bevilacqua A, Canti G and Milanesi L: Systems biology of the metabolic network regulated by the Akt pathway. Biotechnol Adv 30: 131-141, 2012.

26. Wang R, Cong WH, Guo G, Li XX, Chen XL, Yu XN and $\mathrm{Li} \mathrm{H}$ : Synergism between carnosic acid and arsenic trioxide on induction of acute myeloid leukemia cell apoptosis is associated with modulation of PTEN/Akt signaling pathway. Chin J Integr Med 18: 934-941, 2012.

27. Lindsley CW: The Akt/PKB family of protein kinases: a review of small molecule inhibitors and progress towards target validation: a 2009 update. Curr Top Med Chem 10: 458-477, 2010

28. Oki E, Baba H, Tokunaga E, et al: Akt phosphorylation associates with LOH of PTEN and leads to chemoresistance for gastric cancer. Int J Cancer 117: 376-380, 2005.

29. Song L, Xiong H, Li J, et al: Sphingosine kinase-1 enhances resistance to apoptosis through activation of PI3K/Akt/NF-kB pathway in human non-small cell lung cancer. Clin Cancer Res 17: 1839-1849, 2011. 